\title{
Microdontia after chemotherapy in a patient treated for neuroblastoma: Histopathological findings
}

\section{Mikrodoncja po chemioterapii u pacjenta leczonego z powodu nerwiaka zarodkowego - badania histopatologiczne}

\author{
Anna Jodłowska ${ }^{1, A-D}$, Jacek Pają $k^{2, B, C, E}$, Lidia Postek-Stefańska ${ }^{1, E, F}$ \\ 1 Department of Pediatric Dentistry, Medical University of Silesia, Katowice, Poland \\ ${ }^{2}$ Department of Patomorphology and Molecular Diagnostics, Medical University of Silesia, Katowice, Poland \\ A - research concept and design; $B$ - collection and/or assembly of data; $C$ - data analysis and interpretation; \\ $D$ - writing the article; $E$ - critical revision of the article; $F$ - final approval of the article
}

Address for correspondence

Anna Jodłowska

ajodlowska@sum.edu.pl

\section{Funding sources}

Statutory sources (grant No. KNW 1-021/N/7/I).

Conflict of interest

None declared

Received on July 3,2018

Reviewed on August 19, 2018

Accepted on September 10, 2018

\begin{abstract}
Microdontia is one of the late effects of antineoplastic therapy in children. This study is based on the comparative histological examination of abnormal, peg-shaped premolars, erupted in a patient treated for neuroblastoma, and of non-affected teeth, extracted in a healthy child. Apart from the size, the teeth vary in tissue morphology. The number of dentinal tubules, dependent on the number of odontoblasts, is smaller in the microdontal sample when observation in the same-sized field of view is conducted. Moreover, the youngest, more than 100-micrometer-thick layer of the microdontal dentin seems to be the secondary dentin, with crispy-shaped tubules and empty spaces between them. No irregular dentin is deposited in the samples of physiologically developed teeth. The structure of cementum is different as well. Unlike regularly shaped premolars, in which typical 2-layer tissue is seen, in sections of microdontal teeth, only acellular tissue with cementoblasts overlying its surface is present. Thorough analysis of drug administration effects, which are visible in microscopic sections, and of time of anticancer treatment could provide insight into the developmental mechanisms of tooth germ formation.
\end{abstract}

Key words: chemotherapy, histopathology, tooth abnormalities, neuroblastoma

Słowa kluczowe: chemioterapia, histopatologia, zaburzenia zębowe, nerwiak zarodkowy

DOI

$10.17219 / \mathrm{dmp} / 95028$

Copyright

() 2018 by Wroclaw Medical University

and Polish Dental Society

This is an article distributed under the terms of the

Creative Commons Attribution Non-Commercial License

(http://creativecommons.org/licenses/by-nc-nd/4.0/) 


\section{Introduction}

Numerous clinical studies have shown changes in dental morphology after chemotherapy and head radiotherapy. ${ }^{1-7}$ When used together, it is difficult to decide which of these treatment modalities is responsible for developmental anomalies. According to the literature, chemotherapy mainly induces qualitative dental tissue changes, whereas body irradiation can produce both qualitative and quantitative disturbances in enamel and dentin formation. ${ }^{8}$ However, some literature reports based on the examination of patients treated only with multi-agent chemotherapy showed severely altered dental development as well. ${ }^{4,9,10}$ Many experimental histological studies have demonstrated impaired and delayed tooth development after administration of different chemotherapeutics used for human treatment. ${ }^{4,11-17}$ The follow-up in animals was not long enough to show all histological changes. The animal model is not similar to the human model, which prevents depicting quantitative developmental abnormalities. ${ }^{16,17}$ However, analysis of histological experimental findings can be helpful in predicting the effect of chemotherapy. There are different types of toxic effects posed by chemotherapy. It can disturb DNA synthesis or replication and RNA transcription, and thus interfere with the proliferating cell cycle. It can also have an impact on cytoplasmic metabolism in the form of disturbed transport mechanisms. ${ }^{17,18}$

The most common anticancer agents used in pediatric oncology are vincristine (VCR), cyclophosphamide (CPX) and actinomycin. Their cytotoxic mechanisms have been widely demonstrated on animal models. Vincristine - a vinca-alkaloid, the so-called microtubule poison - causes mitotic cessation in the metaphase or death of actively proliferating germinative pulp cells, including preodontoblasts. It also changes the function of mature odontoblasts. ${ }^{12-14}$ The interrupted transport from the rough endoplasmic reticulum to the Golgi complex caused by VCR in ameloblasts, odontoblasts and cementoblasts is well-known side effect. ${ }^{19,20}$ Cyclophosphamide - an alkylating substance - cross-links the guanine bases in DNA, and thus inhibits cell division or leads to mutations in dentin and enamel precursor cells. ${ }^{4,11}$ Actinomycin $\mathrm{D}$ is an intercalating agent - an antibiotic that inserts itself into DNA, leading to its damage and subsequent inhibition of RNA and protein synthesis. Even low doses induce damage in young premature cells, while much higher doses can disturb fully developed secretory ameloblasts and odontoblasts. ${ }^{15}$ However, the above-mentioned cytotoxic mechanisms were presented following a single drug injection and a short follow-up time, related to animal teeth at late development. The abnormalities described were transient and not severe. Severe dental damage is a long-term side effect and may occur after long-term chemotherapy at early developmental stages. ${ }^{4,21}$ Reports based on the histological examination of teeth damaged before the onset of apposition are missing.

\section{Case report}

A male patient at the age of 10 years presented at the Children's Dentistry Outpatient Clinic of the Department of Pediatric Dentistry in Katowice, Poland, for dental evaluation before orthodontic treatment. The intraoral examination revealed no carious lesions and correct oral hygiene. The boy was in the mixed dentition period with only permanent first molars and incisors present. The mandibular primary canines were exfoliated and the permanent successors were ready to erupt, as evidenced by the panoramic radiograph delivered. The germs of permanent first premolars seemed to be absent, which was the reason the orthodontist recommended to remove all the deciduous first molars. Careful analysis revealed that small mineralized structures between the roots of the primary first molars were likely to exist. It was found from a medical history that the patient had received anticancer treatment between 12 months and 2 years of age. The boy received multi-agent chemotherapy with, among other things, VCR, CPX and actinomycin. After exfoliating the mandibular primary first molars and after taking a panoramic radiograph, a diagnosis of microdontia was established (Fig. 1). Finally, a removal of the maxillary primary first molars was planned. At the age of 13 years, the patient returned to our clinic with a recommendation for the extraction of partially erupted microdontal teeth (Fig. 2). The teeth obtained were then fixed with $10 \%$ neutral buffered formalin and sent for histological examination. For a comparative study, the same procedure was performed on 4 fully erupted, non-affected permanent first premolars, removed for orthodontic reasons in a 14-year-old patient with a non-contributory medical history.

After specimen delivery to the Department of Pathomorphology (Medical University of Silesia, Katowice, Poland), a few-month decalcification procedure using a TBD-2 Decalcifier (Fisher Scientific, Hampton, USA) was performed. Subsequently, 4-micrometer-thick paraffin-embedded serial longitudinal sections were prepared. In order to better show discreet dental structures, the specimens were counterstained according to hematoxylin

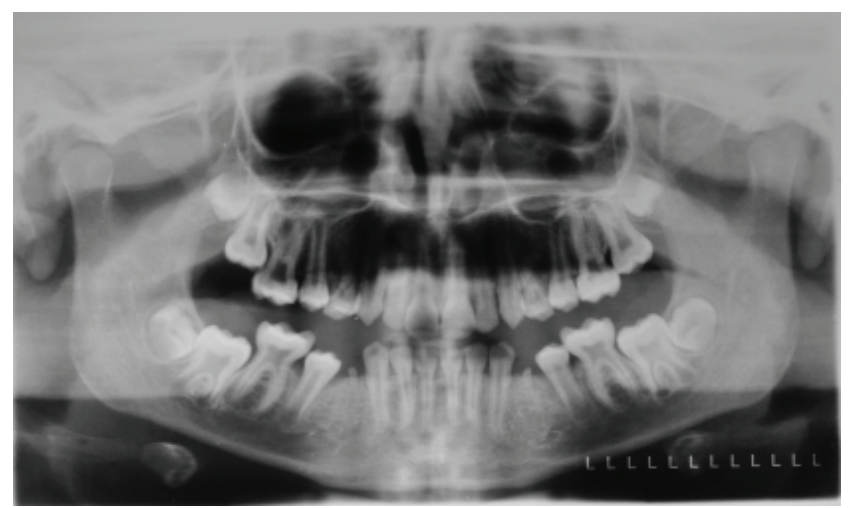

Fig. 1. Panoramic radiograph in the 11-year-old patient. Unerupted microdontal permanent first premolars are clearly visible 


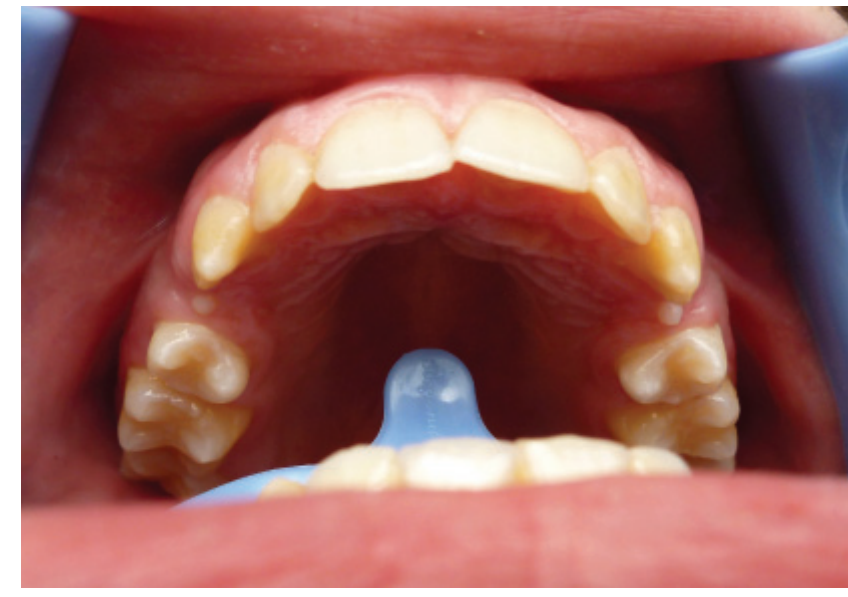

Fig. 2. Clinical image of the upper dental arch of the patient aged 13 years. Partially erupted maxillary first premolars are shown

and eosin (H\&E), periodic acid-Schiff (PAS) and Masson's trichrome protocols. The microscopic images were taken at $\times 40-400$ magnification, using an Olympus BX-51 microscope (Olympus Corporation, Tokyo, Japan) and dedicated cellSens software (Fig. 3-10).

Both the well-shaped and microdontal teeth had their roots fully developed. The microdontal sample was approx. 20 times smaller than its normal counterpart. The results obtained are presented in the Figures, showing the histological structure of the dentin, pulp tissue and cementum. The enamel tissue was destroyed during the decalcification procedure; therefore, it is not visible in the photographs.

The dentine appears as a fibrous compact structure with long tubules passing through its entire width. The number of tubules, dependent on the number of odontoblasts, is smaller in microdontal teeth when observation in the same-sized field of view is conducted. The newly formed tissue adjacent to the pulp, which is termed predentin,

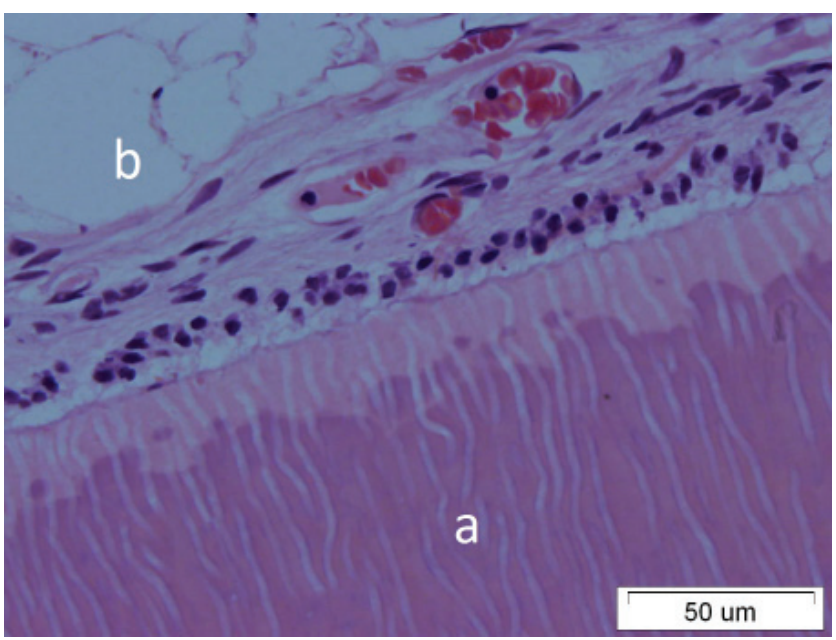

Fig. 3. Microdontal maxillary right first premolar. Dentinal tubules: a - dentin with a decreased number of tubules and brightly stained predentin; $b$ - pulp with darkly stained nuclei of odontoblasts, vessels with blood cells and adipocytes of adipose tissue (H\&E, $\times 400$ magnification) H\&E - hematoxylin and eosin.

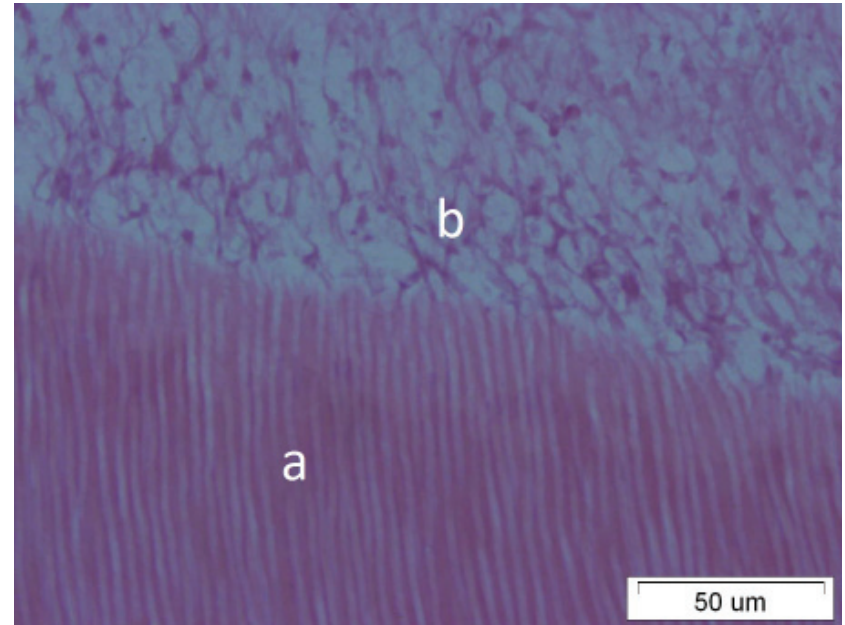

Fig. 4. Non-affected mandibular left first premolar. Dentinal tubules at the same magnification: a - dentin with a high number of tubules and slightly marked predentin; $b$ - pulp with crowded odontoblasts and star-shaped cells of fibrous tissue (H\&E, $\times 400$ magnification) H\&E - hematoxylin and eosin.

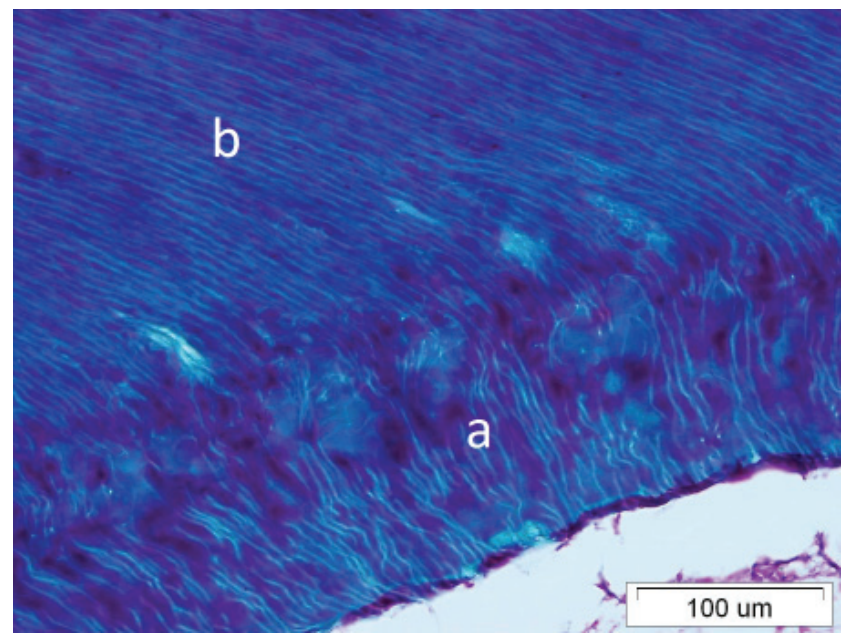

Fig. 5A. Microdontal mandibular left first premolar. Irregular secondary dentin-like tissue with a thickness of approx. $100 \mu \mathrm{m}$ : a - crispy tubules in a decreased number; $b$ - regular tubular pattern of primary dentin (Masson's trichrome, $\times 200$ magnification)

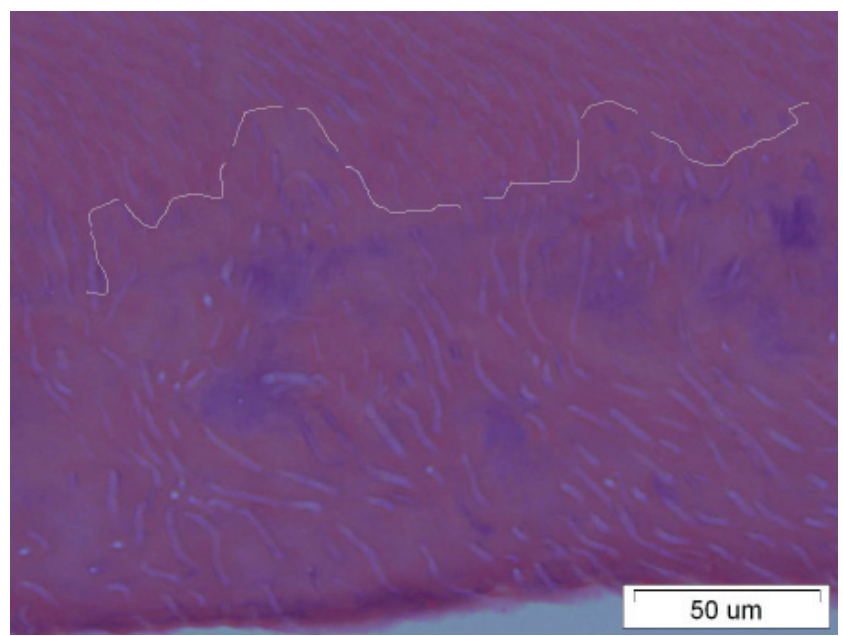

Fig. 5B. Microdontal mandibular left first premolar. Stratum of irregular secondary dentin from Fig. 5A at a higher magnification: the line marks the border between the first deposited primary dentin and irregular secondary tissue ( $H \& E, \times 400$ magnification) H\&E - hematoxylin and eosin. 


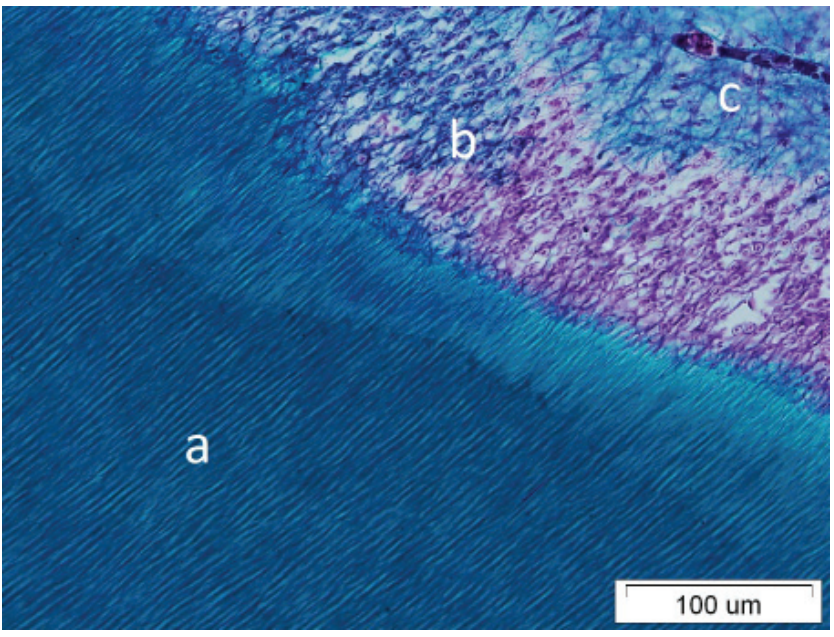

Fig. 6A. Non-affected mandibular left first premolar. Properly built primary tubular dentin without traces of secondary tissue: a - regular pattern of parallel dentinal tubules; $b$ - a multilayer-looking line of odontoblasts; c - star-shaped germinative pulp cells (Masson's trichrome, magnification $\times 200$ )

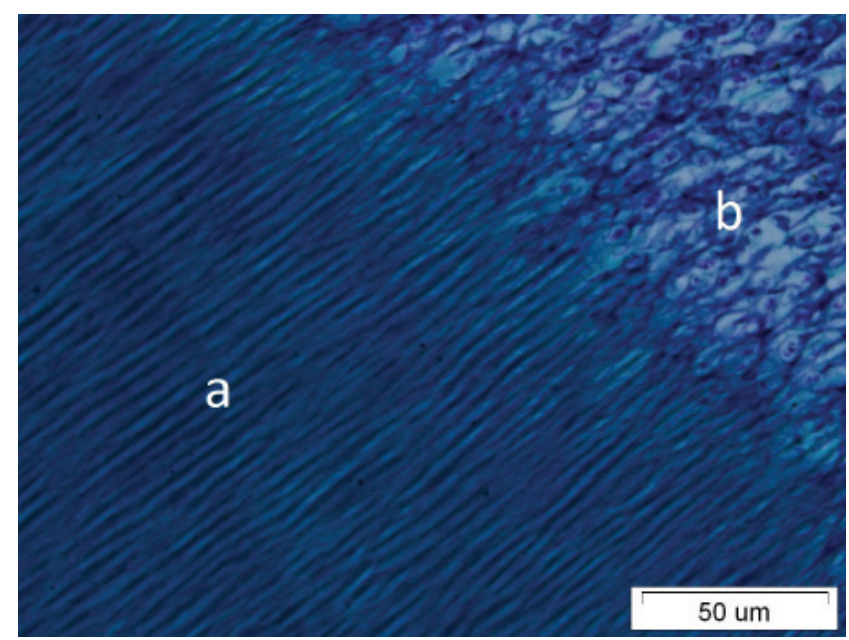

Fig. 6B. Non-affected mandibular left first premolar. Primary dentin from Fig. 6A at a higher magnification: a - inside dentin tubules, blue-stained unmyelinated nerve fibers, originating from pulp; $b$ - odontoblasts (Masson's trichrome, magnification $\times 400$ )

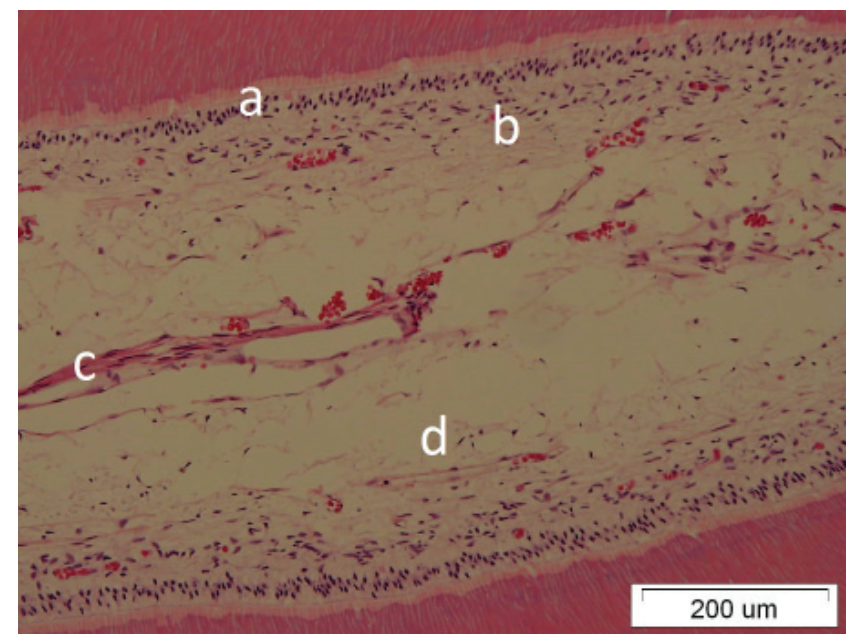

Fig. 7. Microdontal maxillary right first premolar. Dental pulp:

a - odontoblasts - dentin producing cells; $b$ - cell-rich zone; c - collagen fibers adjacent to blood vessels; $d$ - adipocytes ( $H \& E$, magnification $\times 100$ ) H\&E - hematoxylin and eosin.

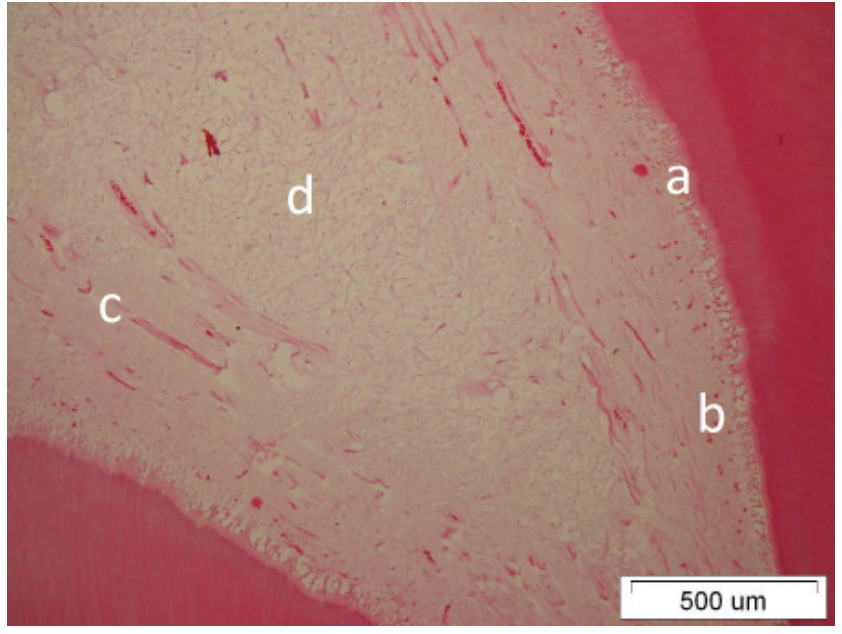

Fig. 8. Non-affected mandibular left first premolar. Dental pulp: a - odontoblasts; $b$ - cell-rich zone; c - collagen fibers; $d$ - adipose tissue (H\&E, magnification $\times 40)$ H\&E - hematoxylin and eosin

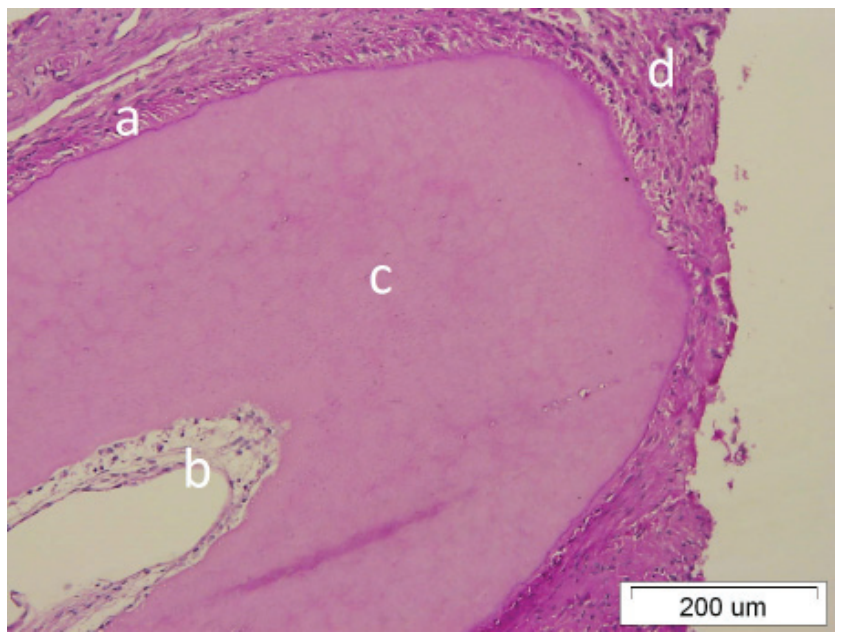

Fig. 9A. Microdontal maxillary right first premolar. Cementum in the apex region: a - 1 layer of acellular fibrous cementum; $b$ - pulp chamber of a small volume; $c$ - tubular dentin; $d$ - periodontal ligament (PAS, magnification $\times 100$ ) PAS - periodic acid-Schiff.

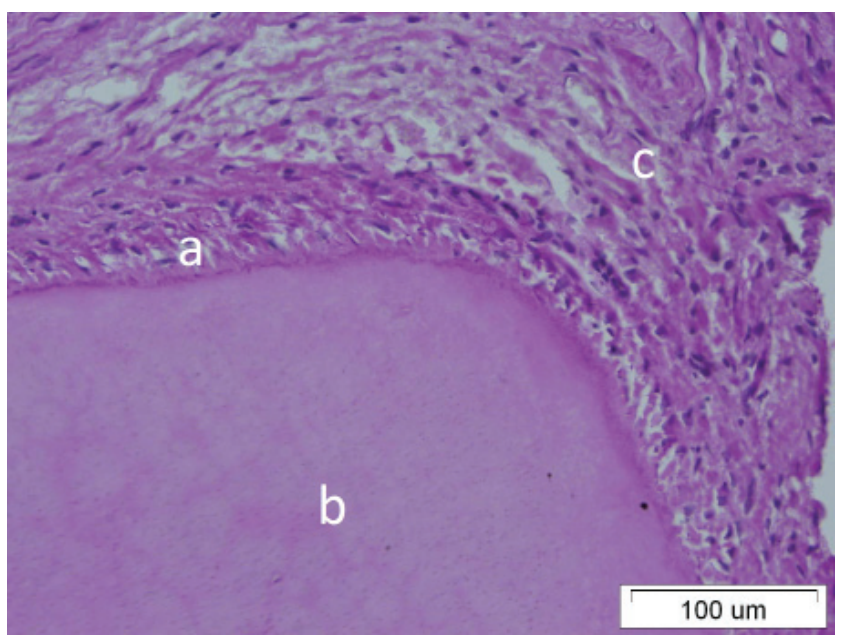

Fig. 9B. Microdontal maxillary right first premolar. Part of cementum from Fig. 9A at a higher magnification: $\mathrm{a}-\mathrm{a}$ thin layer of acellular fibrous cementum covered with cementoblasts; $\mathrm{b}$ - tubular dentin; $\mathrm{c}$ - periodontal ligament with numerous collagen fibers and fibroblasts (PAS, magnification $\times 200$ ) PAS - periodic acid-Schiff. 


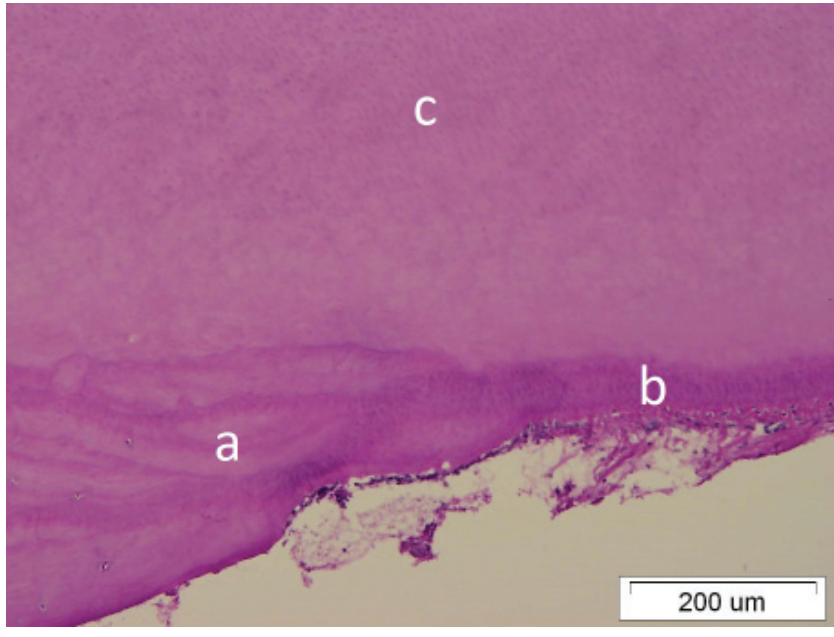

Fig. 10A. Non-affected maxillary right first premolar. Cementum in the apical third of the root: a - typical multilayer cellular cementum with cementocytes embedded inside hard tissue; $b$ - acellular fibrous cementum covered with cementoblasts; $c$ - dentin with obliquely cut tubules (PAS, magnification $\times 100$ )

PAS - periodic acid-Schiff.

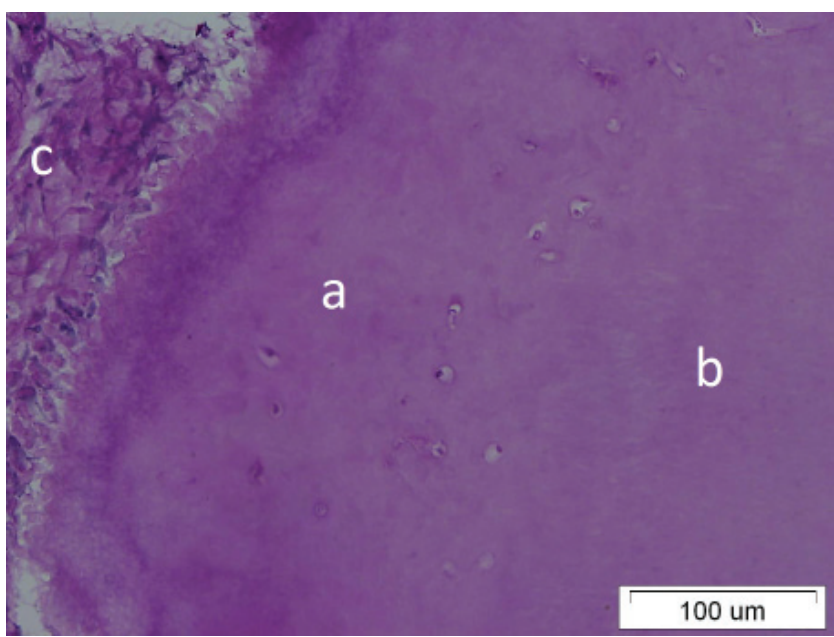

Fig. 10B. Non-affected maxillary right first premolar. Apical cementum at a higher magnification: a - cellular cementum with cementocytes embedded inside hard tissue covered with the stratum of acellular cementum; b - dentin; c - periodontal ligament (PAS, magnification $\times 200$ ) PAS - periodic acid-Schiff.

presents a brighter color in each stain due to lower mineral content. Inside the predentin, the first darkly stained nuclei of calcification are seen (Fig. 3,4). The youngest, more than 100-micrometer-thick layer of the microdontal dentin seems to be the secondary dentin, with crispy-shaped tubules and empty spaces between them (Fig. 5A,5B). No irregular dentin is deposited in the sample of the physiologically developed tooth (Fig. 6A,6B).

The pulp cavity filled with loose connective tissue contains all the layers proper for the dental pulp in the 2 types of teeth (Fig. 7,8). The multilayer-looking line of odontoblasts in the crown region, which are more crowded in pulp extensions, changes when passing through the root canal, from initially cuboidal to flattened cells present in lower numbers. The pulp of the microdontal teeth var- ies in the number of odontoblasts, as evidenced in the photographs showing dentin tubules (Fig. 3,4). Thin unmyelinated nerve fibers originating from the cell-free zone are visible between odontoblasts and penetrate into the tubules of the pulp-adjacent dentin (Fig. 6B). Below dentin-producing cells, the properly built cell-free zone of Weil, the cell-rich zone and the pulp core are situated. The pulp core consists of vascular fibrous tissue with starshaped cells, shown in a higher magnification in Masson's trichrome stain (Fig. 6A).

The structure of cementum differs depending on the type of tooth. In the sections of regular-shaped premolars, typical 2-layer tissue is seen. Internal acellular fiber cementum is covered with multilayer tissue with cementocytes embedded in its structure in the apical third of the root. No traces of cellular cementum in the interradicular area were detected. Externally, the stratum of cementoblasts with dark blue nuclei is noted. In some sections, the layers of cementum are inverted (Fig. 10A,10B). Otherwise, in microdontal teeth, only acellular tissue with cementoblasts overlying its surface is present. Several layers of cellular cementum in the upper premolar were found atypically situated in the cervical part of the root, covering only its one surface (Fig. 9A,9B).

\section{Discussion}

Development of permanent dentition is poorly understood in comparison with primary teeth due to the limitations connected with their postnatal formation. ${ }^{22}$ There is no accurate information regarding the duration of particular developmental stages.

Thorough analysis of anticancer treatment time in relation to the type of tooth abnormality could make it possible to take a look at the mechanisms of odontogenesis. ${ }^{21}$ Some histological studies in which the impact of cytotoxic drugs on dentinogenesis is presented may be found in the literature. Polarized microscopy appeared to be helpful in showing regular incremental lines in the dentin, corresponding to intravenous chemotherapy administration, although the tooth morphology was not changed. ${ }^{23,24}$ The effects of tooth germ impairment occurring before the appositional growth of dental tissues are not welldocumented. Medical sources explain that microdontia succeeds tooth germ injury in the bud stage. ${ }^{25,26}$ The bud stage is described as critical for normal tooth development. Experimental studies have shown that explants from this proliferation stage continue to grow in tissue culture. ${ }^{27}$ In spite of the fact that the tooth morphology pattern is dependent on appropriate gene expression, cytotoxic germ cell injury in an early developmental stage may lead to changes in the programmed developmental model. Among the different theories, a statement may be found that the dental shape is likely to be determined at the tooth initiation, when the epithelium and ectomesen- 
chyme are the only germ components. ${ }^{28}$ Thus, in the case studied, the cytotoxic treatment altered the programmed pattern of premolar formation, leading to the development of the peg-shaped tooth. The small size of first premolars only and the regular morphology of second premolars, developing 7-8 months later, indicates that the first bands of cells at the initiation and bud stage are not prone to injury. At the bell stage, by contrast, tooth shape formation, the so-called morphodifferentiation, is observed. ${ }^{27,28}$ Thus, the duration of the early developmental stages seems to be relatively long compared to the bell stage. Damage can also take place at the bell stage, for example at its early phase. The beginning of apposition for permanent first premolars is reported to occur at the age of 1 year and 3 months up to 2 years. ${ }^{29}$ The treatment was initiated when the patient turned 12 months and was finished at the age of 2 years, shortly before mineralization. In the authors' previous research, the majority of patients with microdontia started their antineoplastic treatment before or at the expected time of the onset of apposition. ${ }^{21}$ This may be the evidence of a short period within the bell stage when the tooth shape is being determined.

The peg-shaped tooth is either small-sized or has no bicuspid features. Histological observations confirmed a narrow pulp cavity with a small number of odontoblasts, resulting in altered dentin appearance. In a study on rat incisors, $24 \mathrm{~h}$ after injection of VCR, almost all preodontoblasts were destroyed. And although after the next $24 \mathrm{~h}$, newly formed vital germinative cells appeared and severely disturbed preodontoblasts were seen incisally, delayed tooth growth was observed. Moreover, the authors observed formation of the irregular dentin, originating from odontoblasts with altered secretion ability due to cytotoxic impairment of functional odontoblasts. The mentioned odontoblasts were not labelled, and thus they could not originate from the proliferative pool of the pulp. ${ }^{12}$ Their function was impaired rather as a result of damaged microtubule proteins - important transport cytoplasmic structures. ${ }^{19,20}$ Immediate lethal and sublethal effects on odontoblasts, non-dividing cells, has also been observed in other studies. Dentinal niche and irregular predentin formation were seen as a result of disturbed matrix synthesis and secretion. The authors also noted that the reparative activity of undifferentiated pulp cells resulted in predentinoid or osteodentin tissue production, corresponding to the area of the injured odontoblasts. ${ }^{13,14}$ In the histological images, an incremental line between the dentin formed before and after VCR administration is additionally present. The irregular osteodentin is situated pulpally to the line. ${ }^{13}$ In the case of our patient, VCR and other administered drugs severely destroyed undifferentiated germinative cells, to such an extent that development of physiologically-sized teeth appeared to be impossible. The abnormal shape was obviously due to the small size. A decreased number of dental papilla cells resulted in poor regeneration of functional odonto- blasts. Although they ensured regular dentin formation, the number of dentinal tubules in the field of view was smaller compared to the control.

Interestingly, the present study showed the presence of a dentin layer resembling the secondary dentin in all the microdontal samples. Many clinical studies have demonstrated alterations in the root developmental pattern after anticancer therapy. A premature apical closure with a decreased root-crown ratio is one of the disturbances described. ${ }^{1-3,5,30}$ This anomaly usually appears when anticancer therapy takes place in the period of root formation. Our patient received chemotherapy a long time before this stage. But the early development of the microdontal crown was probably followed by short-time root formation. Before the extraction of the control teeth, their development had just finished and the secondary dentin could not be observed. After the early finished root development, odontoblasts of the microdontal teeth started secondary dentin production, although the teeth had been removed 1 year before the extraction of the control teeth. The secondary dentin is secreted very slowly; therefore, it is not possible to estimate the time needed for its formation.

Taking into account the above-mentioned findings, it is difficult to understand the differences in the cementum morphology shown in the histological images. The early developed microdontal teeth show no traces of cellular tissue, well-developed in the control group. It is known that the cellular cementum is mostly formed after the tooth reaches the occlusal surface of the opposite tooth. Wider research is needed to explain whether the reason is the severe impairment of ectomesenchymal cells of the dental sac following anticancer therapy. Takuma et al. used a transmission electron microscope to analyze the reaction of the cellular components of cementoblasts after VCR administration. ${ }^{19}$ Based on an observation of a growing apical area of the rat first molar roots, the authors demonstrated the damage of microtubules, and thus transport impairment. However, high dose levels were used in the experiment and reliable results were not obtained. ${ }^{19}$

The dental pulp morphology, besides the shape and size, is similar for the 2 groups of teeth. The number of odontoblasts in the microdontal sample seems to be smaller; thus, dentin formative cells line the cavity in 1 , almost regular layer. Therefore, the basement membrane seen between odontoblasts and the newly formed predentin is well-marked. Otherwise, rich in odontoblasts, the control pulp exhibits its multilayer appearance, although dentin precursor cells form a 1-stratum lining. A large number of dentinal tubules in the control teeth compared to the small number in the microdontal sample confirms this observation.

A comparative histological examination of abnormal peg-shaped premolars erupted in a patient treated for neuroblastoma and non-affected teeth extracted in a healthy child showed differences in tissue morphology. 
Unlike the regular-shaped premolars, the microdontal sections are characterized by the presence of an irregular dentin layer, a relatively smaller number of odontoblasts and the absence of cellular tissue in the cementum morphology. The anticancer therapy was initiated shortly before the onset of mineralization, at the early stage of first premolar development. Thorough analysis of drug administration effects visible in microscopic sections and of time of anticancer treatment can provide insight into the developmental mechanisms of tooth germ formation.

\section{References}

1. Avşar A, Darka O, Pinarli G. Long-term effects of chemotherapy on caries formation, dental development and salivary factors in childhood cancer survivors. Oral Surg Oral Med Oral Pathol Oral Radiol Endod. 2007;104(3):781-789.

2. Marec-Berard P, Chaux-Bodard AG, Lagrange H, Azzi D, Gourmet R, Bergeron C. Long-term effects of chemotherapy on dental status in children treated for nephroblastoma. Pediatr Hematol Oncol. 2005;22(7):581-588.

3. Hölttä P, Alaluusua S, Saarinen-Pihkala UM, Peltola J, Hovi L. Agenesis and microdontia of permanent teeth as late adverse effects after stem cell transplantation in young children. Cancer. 2005;103(1):181-190.

4. Minicucci EM, Lopes LF, Crocci AJ. Dental abnormalities in children after chemotherapy treatment for acute lymphoid leukemia. Leuk Res. 2003;27(1):45-50.

5. Hölttä P, Alaluusua S, Saarinen-Pihkala UM, Wolf J, Nyström M, Hovi L. Long-term adverse effects on dentition in children with high-dose chemotherapy and autologous stem cell transplantation with or without total body irradiation. Bone Marrow Transplant. 2002;29(2):121-127.

6. Kaste SC, Hopkins KP, Jenkins JJ. Abnormal odontogenesis in children treated with radiation and chemotherapy: Imaging findings. AJR Am J Roentgenol. 1994;162(6):1407-1411.

7. Pajari U, Lanning M, Larmas M. Prevalence and location of enamel opacities in children after anti-neoplastic therapy. Community Dent Oral Epidemiol. 1988;16(4):222-226.

8. Dahllöf G, Rozell B, Forsberg CM, Borgström B. Histologic changes in dental morphology induced by high-dose chemotherapy and total body irradiation. Oral Surg Oral Med Oral Pathol. 1994;77(1):56-60.

9. Remmers D, Bökkerink JPM, Katsaros C. Microdontia after chemotherapy in a child treated for neuroblastoma. Orthod Craniofac Res. 2006;9(4):206-210.

10. Kaste SC, Hopkins KP, Bowman LC, et al. Dental abnormalities in children treated for neuroblastoma. Med Pediatr Oncol. 1998;30(1):22-27.

11. Näsman M, Forsberg CM, Dahllöf G. Long-term dental development in children after treatment for malignant disease. Eur J Orthod. 1997;19(2):151-159.

12. Stene T, Koppang HS. Autoradiographic investigation of proliferative responses in rat incisor pulp after vincristine administration. Scand J Dent Res. 1980;88(2):96-103.

13. Stene T. Vincristine's effect on dentinogenesis in rat incisor. Scand J Dent Res. 1979;87(1):39-49.

14. Stene T. Effect of vincristine on odontoblasts in rat incisors. Scand J Dent Res. 1978;86(5):346-356.

15. Lyaruu DM, van Duin MA, Bervoets TJM, Wöltgens JH, Bronckers AL. Effects of actinomycin $D$ on developing hamster molar tooth germs in vitro. Eur J Oral Sci. 1997;105(1):52-58.

16. de Oliveira Nogueira T, Stene T, Koppang HS. Long-terms effects of colchicine on dentinogenesis in rat incisors. Scand J Dent Res. 1980;88(1):15-21.

17. Dahl JE. Influence of doxorubicin on rat incisor mesenchymal cells. Scand J Dent Res. 1984;92(1):6-13.

18. Goho C. Chemoradiation therapy: Effect on dental development. Pediatr Dent. 1993;15(1):6-12.

19. Takuma S, Sawada T, Yama S, Yanagisawa T. Ultrastructural changes in the cementoblasts of rat molars after injection of vincristine. J Dent Res. 1984;63(9):1108-1115.
20. Takuma S, Sawada T, Yanagisawa T. Ultrastructural changes of secreting rat-incisor ameloblasts following administration of vincristine and vinblastine. J Dent Res. 1982;61(Spec No):1472-1478.

21. Jodłowska A, Postek-Stefańska L, Pietraszewska D, et al. Tooth development in the light of cancer survivors' examination. J Stoma. 2016;69:659-666.

22. Olley RC, Xavier GM, Seppala M, et al. Expression analysis of candidate genes regulating successional tooth formation in the human embryo. Front Physiol. 2014;5:445.

23. Macleod RI, Welbury RR, Soames JV. Effects of cytotoxic chemotherapy on dental development. J R Soc Med. 1987;80(4):207-209.

24. Maguire A, Craft AW, Evans RGB, et al. The long-term effects of treatment on the dental condition of children surviving malignant disease. Cancer. 1987;60(10):2570-2575.

25. Bath-Balogh M, Fehrenbach MJ. Illustrated Dental Embryology, Histology, and Anatomy. Philadelphia, PA: W.B. Saunders Company; 1997:65.

26. Fehrenbach MJ. Review of tooth development and associated developmental disturbances. J Pract Hyg. 2000;5-6:12-14.

27. Kumar GS. Orban's Oral Histology and Embryology. $13^{\text {th }}$ ed. Gurgaon, India: Elsevier India; 2011:27-38.

28. Nanci A. Ten Cate's Oral Histology. Development, Structure and Function. $8^{\text {th }}$ ed. St. Louis, MO: Mosby; 2012:70-89.

29. Cameron AC, Widmer RP. Handbook of Pediatric Dentistry. $3^{\text {rd }}$ ed. St. Louis, MO: Mosby Elsevier; 2008:458-459.

30. Rosenberg SW, Kolodney H, Wong GY, Murphy ML. Altered dental root development in long-term survivors of pediatric acute lymphoblastic leukemia. Cancer. 1987;59(9):1640-1648. 
